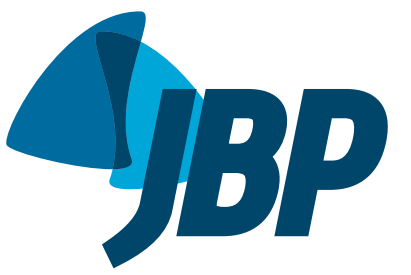

\title{
Evolution in the management of non-small cell lung cancer in Brazil
}

\author{
Caio Júlio Cesar dos Santos Fernandes ${ }^{1,2}$
}

Lung cancer, and its most prevalent variant-non-small cell lung cancer (NSCLC)-is responsible for $85 \%$ of all lung cancer cases ${ }^{(1)}$ and is a significant cause of death in the world, as well as in Brazil. It is estimated that, in 2012, approximately 1.6 million deaths occurred due to NSCLC worldwide. (2) In Brazil, in the same year, 23,493 deaths were identified due to this condition. ${ }^{(3)}$

Although the absolute numbers are alarming, lung cancer mortality has been changing over the years. In the mid-1950s, lung cancer became the leading cause of cancer-related deaths in males, and, from the 1980s on, the same phenomenon has occurred in female patients. Since then, there has been a gradual reduction in the number of deaths from lung cancer, mainly due to the decrease in smoking. ${ }^{(4)} \mathrm{A}$ series of improvements in the treatment of patients with NSCLC, such as advances in surgical and radiotherapy techniques, in the perioperative care, and in the systemic treatment, have also helped, in some degree, to reduce the mortality rates of the disease. In fact, the advances in chemotherapy are really remarkable. In the past decade, the identification of molecular mechanisms of tumors allowed a better adaptation of chemotherapy concerning the patient, maximizing its effectiveness and reducing its side effects, both in patients with metastatic disease and in those presenting with recurrence after the initial surgical treatment or radiotherapy. Today, specific therapies are available for patients with EGFR, anaplastic lymphoma kinase $(A L K)$, and oncogene 1 (ROS1) gene mutations. ${ }^{(5)}$ Even when gene mutations are not identified, patients can be submitted to immunotherapy as the first line of treatment when the expression of programmed death ligand $1(P D-L 1)$ is identified in at least $50 \%$ of the tumor cells. ${ }^{(6)}$

In Brazil, however, most of these therapeutic advances are yet to be available on a large scale; even so, there has been a decrease in the absolute number of deaths due to NSCLC in the country. By 2017, it is estimated that the number of deaths in males and females, respectively, will decrease by $7.5 \%$ and $4.8 \%$ when we compare it with recent data from 2012.(3) Would there be Brazilian national data that justify this reduction? Recent epidemiological data show that, despite being smaller, the medium-term prognosis of patients with NSCLC is still rather bleak, with a five-year mortality rate of $86 \%$. ${ }^{(7)}$ However, various advances in this area have also been described in Brazil. Recent studies have evaluated the introduction of new surgical techniques, such as videoassisted thoracic surgery, video-assisted thoracoscopy, ${ }^{(8,9)}$, and robotics ${ }^{(10)}$ in our country. Improvements in early diagnosis have also been described in our setting, with the use of endoscopic ultrasonography for mediastinal staging, ${ }^{(11,12)}$ as well as for the management of more peripheral suspicious lesions ${ }^{(13)}$ that were not previously amenable to a minimally invasive approach. Health care in thoracic oncology referral centers has also been shown to have a positive impact on the prognosis of patients with NSCLC in Brazil, when compared with that in general hospitals. ${ }^{(7)}$ Finally, advances in the management of complications not directly related to the progression of the disease, such as venous thromboembolism, ${ }^{(14)}$ has also benefited this population in a very significant way.

In the present issue of JBP, Franceschini et al. ${ }^{(15)}$ provide relevant information on the epidemiology of patients with NSCLC in Brazil. In their retrospective cohort involving 790 patients from a tertiary center in the city of São Paulo, Brazil, who were followed between 2000 and 2012, the distribution of patients with NSCLC was heterogeneous: in younger patients ( $<72$ years of age) and in women, the predominant histological type was adenocarcinoma. In men older than 72 years of age, the predominant histological type was epidermoid carcinoma. Although NSCLC is still more prevalent in males, the number of women with the disease has been increasing. These data are consistent with those in another cohort study recently published in the JBP. ${ }^{(16)}$ In that study, involving 1,030 patients with NSCLC submitted to surgical treatment between 1986 and 2015, the prevalence of adenocarcinoma in women increased from 11.9\%-in the period between 1986 and 1985-to $24.0 \%$-in the period between 2006 and 2015. These data are also consistent with those in the international literature, such as in a cohort study in the USA. ${ }^{(17)}$ Thus, females, younger individuals, and never smokers (who potentially present with genetic mutations that can be treated with specific therapies) have become more and more important in the global and national NSCLC scenario, and, therefore, they should be better understood and evaluated.

Another relevant aspect reported by Franceschini et al. ${ }^{(15)}$ concerns mortality. No differences regarding mortality were found in the different age groups evaluated. The elderly patient is, by definition, more fragile, mainly due to the presence of comorbidities. Thus, some international consensuses suggest specific approaches for the elderly population with NSCLC. ${ }^{(18)}$ Epidemiological data in Brazil showing that the elderly population does not necessarily have a worse prognosis than has the general population should stimulate the use of this type of protocol, so that these patients can benefit from the advances in the 
treatment of NSCLC, with a better adapted therapeutic approach.

More and more national data on NSCLC patients have become available, and this is a fact to be celebrated. It is very important that international evidence, as well as technological and pharmacological innovations, on the management of NSCLC be disseminated; however, it is fundamental that we should be aware of our reality on this topic, so that, by recognizing our vulnerabilities and demands, we will be able to offer these innovations to our patients in a more efficient, safe, and cost-effective manner.

\section{REFERENCES}

1. Travis WD. Pathology of lung cancer. Clin Chest Med. 2011:32(4):669 92. https://doi.org/10.1016/j.ccm.2011.08.005

2. Brambilla E, Travis W. Lung cancer. In: Stewart BW, Wild CP, editors, World Cancer Report 2014. Geneva: World Health Organization 2014.

3. Carioli G, La Vecchia C, Bertuccio P, Rodriguez T, Levi F, Boffetta $P$, et al. Cancer mortality predictions for 2017 in Latin America. Ann Oncol. 2017;28(9):2286-2297. https://doi.org/10.1093/annonc/ $\mathrm{mdx} 301$

4. Jemal A, Simard EP, Dorell C, Noone AM, Markowitz LE, Kohler B et al. Annual Report to the Nation on the Status of Cancer, 1975 2009, featuring the burden and trends in human papillomavirus(HPV)associated cancers and HPV vaccination coverage levels. J Nat Cancer Inst. 2013;105(3):175-201. https://doi.org/10.1093/jnci/djs491

5. Sholl LM. Biomarkers in lung adenocarcinoma: a decade of progress Arch Pathol Lab Med. 2015;139(4):469-80. https://doi.org/10.5858/ arpa.2014-0128-RA

6. Brahmer J, Reckamp KL, Baas P, Crino L, EberhardtWE, Poddubskaya $\mathrm{E}$, et al. Nivolumab versus Docetaxel in Advanced Squamous-Cell Non-Small-Cell Lung Cancer. N Engl J Med. 2015;373(2):123-35. https://doi.org/10.1056/NEJMoa1504627

7. Souza MC, Cruz OG, Vasconcelos AG. Factors associated with disease-specific survival of patients with non-small cell lung cancer J Bras Pneumol. 2016:42(5):317-325. https://doi.org/10.1590/S180637562015000000069

8. Terra RM, Kazantzis T, Pinto-Filho DR, Camargo SM, Martins-Neto F, Guimarães AN, et al. Anatomic pulmonary resection by videoassisted thoracoscopy: the Brazilian experience (VATS Brazil study). J Bras Pneumol. 2016;42(3):215-21. https://doi.org/10.1590/S180637562015000000337

9. Soder SA, Barth F, Perin FA, Felicetti JC, Camargo JJP, Camargo $\mathrm{SM}$. Anatomic pulmonary resection via video-assisted thoracic surgery: analysis of 117 cases at a referral center in Brazil. J Bras Pneumol. 2017;43(2):129-133. https://doi.org/10.1590/s180637562015000000352

10. Terra RM, Araujo PH, Lauricella LL, Campos JR, Costa HF, PegoFernandes PM. Robotic pulmonary lobectomy for lung cance treatment: program implementation and initial experience. J Bras Pneumol. 2016;42(3):185-90. https://doi.org/10.1590/S1806 37562015000000212

11. Figueiredo VR, Cardoso PF, Jacomelli M, Demarzo SE, Palomino AL, Rodrigues AJ, et al. Endobronchial ultrasound-guided transbronchia needle aspiration for lung cancer staging: early experience in Brazil. J Bras Pneumol. 2015;41(1):23-30. https://doi.org/10.1590/S180637132015000100004

12. Steinhauser Motta JP, Kempa AT, Pinto Cardoso A, Paschoal ME Raggio Luiz R, Lapa E Silva JR, et al. Endobronchial ultrasound in real life: primary diagnosis and mediastinal staging of lung cancer in patients submitted to thoracic surgery. BMC Pulm Med. 2016;16(1):101. https://doi.org/10.1186/s12890-016-0264-7

13. Jacomelli M, Demarzo SE, Cardoso PF, Palomino AL, Figueiredo VR Radial-probe EBUS for the diagnosis of peripheral pulmonary lesions. J Bras Pneumol. 2016;42(4):248-253. https://doi.org/10.1590/s180637562015000000079

14. Fernandes CJ, Alves Junior JL, Gavilanes F, Prada LF, Morinaga LK, Souza R. New anticoagulants for the treatment of venous thromboembolism. J Bras Pneumol. 2016;42(2):146-54. https://doi. org/10.1590/S1806-37562016042020068

15. Franceschini JP, Jamnik S, Santoro IL. Survival in a cohort of patients with lung cancer: the role of age and gender in prognosis. J Bras Pneumol. 2017;43(6):xxx-xxx. https://doi.org/10.1016/1. jtho.2016.11.327

16. Tsukazan MTR, Vigo A, Silva VDD, Barrios $\mathrm{CH}$, Rios JO, Pinto JAF Lung cancer: changes in histology, gender, and age over the last 30 years in Brazil. J Bras Pneumol. 2017;43(5):363-367. https://doi. org/10.1590/s1806-37562016000000339

17. Richards TB, Henley SJ, Puckett MC, Weir HK, Huang B, Tucker $\mathrm{TC}$, et al. Lung cancer survival in the United States by race and stage (2001-2009): Findings from the CONCORD-2 study. Cancer 2017;123 Suppl 24:5079-5099. https://doi.org/10.1002/cncr.31029

18. Dalwadi SM, Szeja SS, Bernicker EH, Butler EB, Teh BS, Farach AM. Practice Patterns and Outcomes in Elderly Stage I Non-Smallcell Lung Cancer: A 2004 to 2012 SEER Analysis. Clin Lung Cancer. 2017. pii: S1525-7304(17)30316-9 